\title{
Spatial-time analysis of cardiovascular emergency medical requests: enlightening policy and practice
}

\author{
Ali Azimi ${ }^{1}$, Nasser Bagheri ${ }^{2}$, Sayyed Mostafa Mostafavi ${ }^{1}$, Mary Anne Furst ${ }^{2}$, Soheil Hashtarkhani ${ }^{1}$, \\ Fateme Hashemi Amin ${ }^{1}$, Saeid Eslami ${ }^{1}$, Fatemeh Kiani ${ }^{1}$, Reza VafaeiNezhad ${ }^{3}$, Toktam Akbari ${ }^{4}$, Amin Golabpour ${ }^{5}$ and \\ Behzad Kiani ${ }^{1 *}$ D
}

\begin{abstract}
Background: Response time to cardiovascular emergency medical requests is an important indicator in reducing cardiovascular disease (CVD) -related mortality. This study aimed to visualize the spatial-time distribution of response time, scene time, and call-to-hospital time of these emergency requests. We also identified patterns of clusters of CVD-related calls.

Methods: This cross-sectional study was conducted in Mashhad, north-eastern Iran, between August 2017 and December 2019. The response time to every CVD-related emergency medical request call was computed using spatial and classical statistical analyses. The Anselin Local Moran's / was performed to identify potential clusters in the patterns of CVD-related calls, response time, call-to-hospital arrival time, and scene-to-hospital arrival time at small area level (neighborhood level) in Mashhad, Iran.
\end{abstract}

Results: There were 84,239 CVD-related emergency request calls, 61.64\% of which resulted in the transport of patients to clinical centers by EMS, while $2.62 \%$ of callers (a total of 2218 persons) died before EMS arrival. The number of CVDrelated emergency calls increased by almost 7\% between 2017 and 2018, and by 19\% between 2017 and 2019. The peak time for calls was between 9 p.m. and 1 a.m., and the lowest number of calls were recorded between 3 a.m. and 9 a.m. Saturday was the busiest day of the week in terms of call volume. There were statistically significant clusters in the pattern of CVD-related calls in the south-eastern region of Mashhad. Further, we found a large spatial variation in scene-to-hospital arrival time and call-to-hospital arrival time in the area under study.

Conclusion: The use of geographical information systems and spatial analyses in modelling and quantifying EMS response time provides a new vein of knowledge for decision makers in emergency services management. Spatial as well as temporal clustering of EMS calls were present in the study area. The reasons for clustering of unfavorable time indices for EMS response requires further exploration. This approach enables policymakers to design tailored interventions to improve response time and reduce CVD-related mortality.

Keywords: Cardiovascular disease, Emergency medical services, Spatial analysis, Geographical information systems, Ambulance services, Response time, Spatial-time

\footnotetext{
* Correspondence: Kiani.Behzad@gmail.com

'Department of Medical Informatics, School of Medicine, Mashhad University of Medical Sciences, Mashhad, Iran

Full list of author information is available at the end of the article
}

(c) The Author(s). 2021 Open Access This article is licensed under a Creative Commons Attribution 4.0 International License, which permits use, sharing, adaptation, distribution and reproduction in any medium or format, as long as you give appropriate credit to the original author(s) and the source, provide a link to the Creative Commons licence, and indicate if changes were made. The images or other third party material in this article are included in the article's Creative Commons licence, unless indicated otherwise in a credit line to the material. If material is not included in the article's Creative Commons licence and your intended use is not permitted by statutory regulation or exceeds the permitted use, you will need to obtain permission directly from the copyright holder. To view a copy of this licence, visit http://creativecommons.org/licenses/by/4.0/. The Creative Commons Public Domain Dedication waiver (http://creativecommons.org/publicdomain/zero/1.0/) applies to the data made available in this article, unless otherwise stated in a credit line to the data. 


\section{Background}

Non-communicable diseases accounted for about $73 \%$ of the total number of deaths worldwide in 2016. Of these, cardiovascular disease (CVD) was the primary cause of premature mortality, accounting for an estimated total of 9.48 million deaths worldwide, signifying a 19\% increase between 2006 and 2016 [1, 2]. In Iran, there were 90,000 reported CVD-related mortalities in 2016, amounting to $25 \%$ of the total number of deaths [3]. This is despite the fact that premature CVD mortalities can often be prevented with timely delivery of emergency medical services [3]. Therefore, reducing the response time in CVD-related emergency requests is of great importance.

CVDs include ischemic heart disease or coronary artery disease (CAD) such as angina and myocardial infarction (MI) (commonly known as a heart attack), cerebrovascular disease (e.g. stroke), diseases of the aorta and arteries, including hypertension and peripheral vascular disease, congenital heart disease, rheumatic heart disease, cardiomyopathies and cardiac arrhythmias [4]. MI has the highest mortality rate compared to other conditions, and occurs as a result of a complete blockage of one of the main coronary arteries [5]. The standard clinical procedure in the treatment of MI is to restore blood flow in the blocked artery in order to avoid myocardial necrosis and restore heart function, thus reducing the risk of death. Damage to the heart muscle as a result of MI increases with time from the blockage of the artery. Interventions that facilitate the diagnosis and treatment of MI can thus potentially lead to reduced CVD-related mortalities and associated complications, and improve patients' quality of life [6-8].

In Iran, the emergency medical services (EMS) are responsible for transferring patients to clinical centers. A patient experiencing a cardiovascular event calls 115, following which an ambulance is dispatched to the patient's residence (scene) to assess their health status and, if deemed necessary, transfer them to the nearest health care center. Response time measures the period between a patient's call and ambulance arrival at the scene. A quick response time is critical to enable effective delivery of clinical intervention in cardiovascular emergencies. To the best of our knowledge, no research has been conducted analyzing EMS response time for CVD incidents in Iran. Estimating and visualizing an index of EMS response time will provide essential knowledge to enable policymakers, healthcare providers and clinicians to improve response time, and ultimately reduce MI mortality rate. This response time index also needs to be adjusted to account for patients' geographical locations and daily time periods.

Geographical information systems (GIS) is an emerging area of research increasingly being used as a decision support tool for policy makers in developing tailored interventions in healthcare [9-12]. GIS is a powerful tool to collect, manage, analyze and represent geo-referenced health data, and to identify gaps in healthcare systems [12-14]. GIS enables researchers to integrate spatial (location of health care services as geographical entities: patient locations and ambulances dispatch centers) and non-spatial data (descriptive information on geographical entities; opening hours, waiting list, etc.) into one framework to provide better informed decision making [15]. There are several international research reports on the application of GIS to the modelling of spatial accessibility and response time to EMS. The main focus points of these studies were: measuring spatio-temporal accessibility [16]; spatial variations of EMS and travel distance [17]; spatial diversity of response time for EMS [18]; the geographictime distribution of all ambulance calls and hourly and weekly EMS call volumes [19]; and conditional autoregressive spatial models to identify drivers of cardiac arrest [20].

To our knowledge, there is no study in Iran which examines the space-time pattern of CVD-related emergency medical requests. The purpose of the present study is to perform a spatial-time analysis, using GIS, of cardiovascular emergency medical requests in Mashhad, Iran. Our specific objectives are to: 1) estimate the first index of response time for CVD-related EMS calls in Iran; and 2) investigate potential clusters in the pattern of CVD-related calls over time and space.

\section{Methods}

\section{Study area and data sources}

This cross-sectional study was conducted in Mashhad, north-eastern Iran, which has a population of 3,785,567 (Fig. 1). Mashhad is the most popular tourist destination and the second most populous city in Iran [21]. Mashhad has 149 neighborhoods which are divided into census blocks, the smallest unit of spatial divisions in cities of Iran. In this study, we used neighborhood catchment as the geographical scale for performing the spatial analyses. Mashhad neighborhoods have an average population of 18,523 and a mean area of $1.92 \mathrm{~km}^{2}$.

\section{Data sources}

Two different data sources were used. First, data from CVD-related emergency calls were obtained from Mashhad Emergency Medical Center. The data did not contain cerebrovascular disease (e.g. stroke) incidents. Second, the spatial division of Mashhad and population data were obtained through the city municipality. The latitude and longitude for all EMS call requests were saved in the EMS database. Therefore, we did not need to geocode the data. We linked the GIS layers and EMS databases to build the geodatabase. 


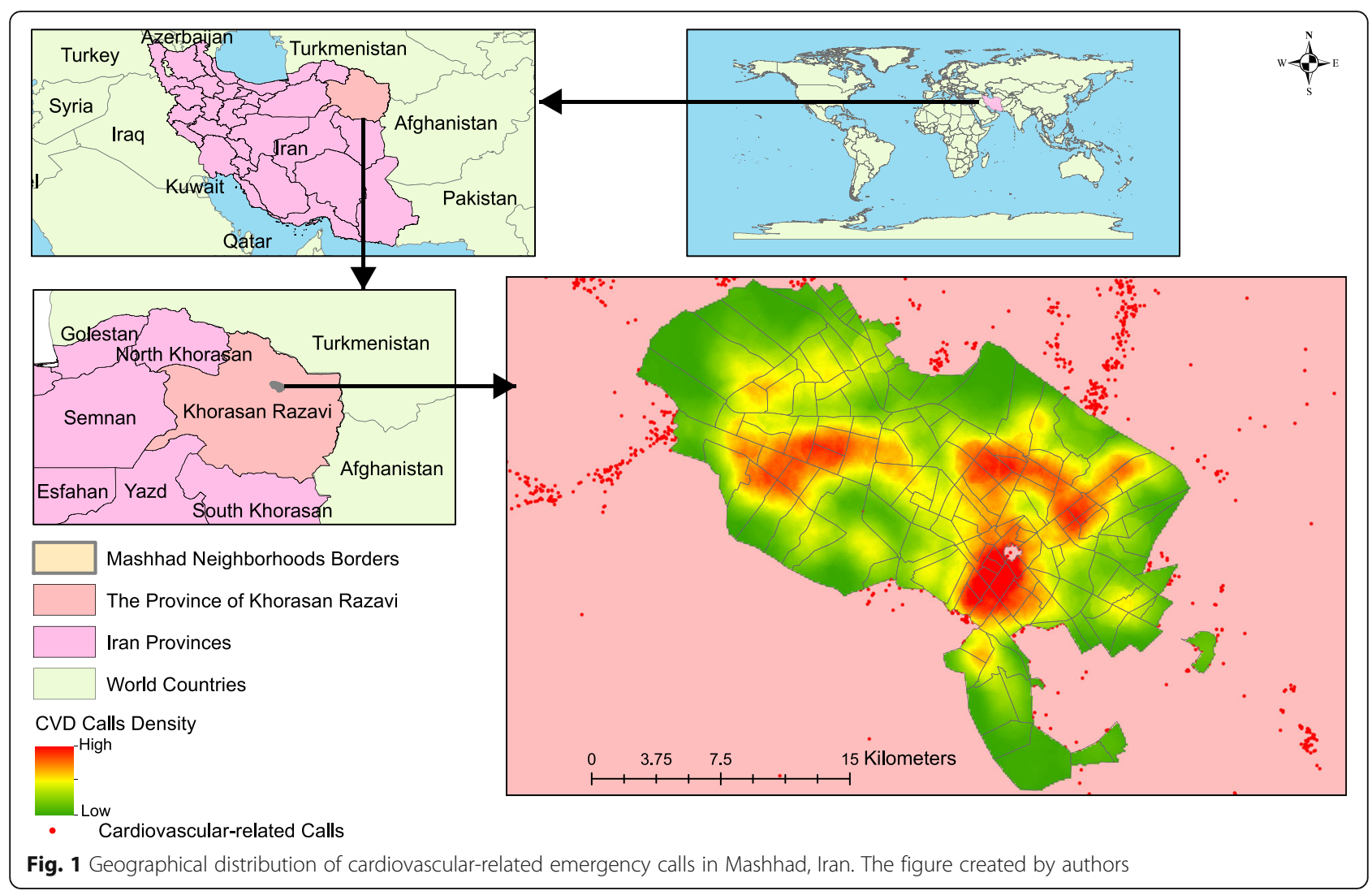

\section{Descriptive analysis}

All descriptive analyses (cross tabulations and frequency indices) were performed using Excel version 2016. Descriptive maps were generated using natural break classification with five classes. Natural break classification is a data grouping method designed to determine the best arrangement of values into different classes. This is conducted by seeking to minimize each class's average deviation from the class mean, while maximizing each class's deviation from the means of the other groups. In other words, the method seeks to reduce the variance within classes and maximize the variance between classes [22]. ArcGIS 10.5 was used for creating the descriptive maps and spatial-time analyses.

\section{Cluster and outlier analysis}

The incidence rate of CVD-related emergency calls was calculated using total population and number of calls in each neighborhood across the study area. The Anselin Local Moran's I statistic was performed to quantify spatial autocorrelation of call frequency at the neighborhood level. This test calculates a $\mathrm{z}$-score and $p$-value to determine whether the apparent similarity (a spatial clustering of either high or low values) or dissimilarity (a spatial outlier) is more pronounced than one would expect in a random distribution. The null hypothesis states that CVD-related emergency calls are randomly distributed across the study area. Areas with HighHigh and Low-Low clusters indicate that the target neighborhood is encompassed by neighborhoods with similar rates of CVD-related emergency calls, while High-Low and Low-High regions show that the target area is encompassed by regions with dissimilar rates of CVD-related emergency calls [9]. In other words, the High-High and Low-Low areas indicate clusters of CVD-related emergency calls occurrence, but the HighLow and Low-High areas indicate outliers of CVD-related emergency call frequencies.

\section{Statistical significance}

Anselin local Moran's $I$ calculates a z-score and $p$-value for each feature in the dataset. $P$-value and $z$-score are closely associated. The p-value is the probability that the observed spatial pattern was created by some random process. A high positive $\mathrm{z}$-score for a feature indicates that the surrounding features (neighboring CVD-related call values) have similar values (either high values or low values). However, a low negative $\mathrm{z}$-score for a feature indicates a statistically significant spatial data outlier. Table 1 shows the range of $\mathrm{z}$-scores and $p$ values used for testing the statistical significance. We used a 95\% confidence level in this study, and all clusters and outliers found in this study were significant at this confidence level. 
Table 1 Z-score and p-value ranges of Anselin local Moran's I

\begin{tabular}{lll}
\hline Z-score (standard deviations) & $\begin{array}{l}\boldsymbol{P} \text {-value } \\
\text { (probability) }\end{array}$ & $\begin{array}{l}\text { Confidence } \\
\text { level }\end{array}$ \\
\hline$<-1.65$ or $>+1.65$ & $<0.10$ & $90 \%$ \\
$<-1.96$ or $>+1.96$ & $<0.05$ & $95 \%$ \\
$<-2.58$ or $>+2.58$ & $<0.01$ & $99 \%$ \\
\hline
\end{tabular}

\section{Results}

Figure 1 shows the geographical distribution of CVDrelated emergency calls in Mashhad from August 2017 until the end of 2019. There were 84,239 calls, the characteristics of which have been mapped in Table 2 . It shows that only $61.64 \%$ of individuals making calls were transferred to a hospital, a figure which remained stable for each year of the study. Furthermore, on average, $2.62 \%$ of callers (2218 persons) died before ambulance arrival, 34.7\% refused transfer to hospital, and for 1.04\% of patients, basic services were provided by EMS technicians, along with a recommendation to personally attend a medical center for follow-up care. The mean age of men was lower than that of women $(P<0.001)$. The response time decreased from $12.33 \mathrm{~min}$ in 2017 to 11.07 min in $2019(P<0.001)$, but the time from leaving the patient's location to arriving at hospital increased from $10.21 \mathrm{~min}$ in 2017 to $12.13 \mathrm{~min}$ in $2019(P<0.001)$.
Figure 2 shows the monthly temporal trend of CVDrelated emergency calls in the study area between 2017 and 2019. It indicates that the number of CVD-related emergency calls increased by almost 7\% between 2017 and 2018, and by 19\% between 2017 and 2019. This is despite a mere $1.7 \%$ annual population growth rate in the city during this period. The figure also reveals that most CVD-related emergency calls occurred in November and December.

Figure 3 shows the seasonal distribution of CVDrelated calls in Mashhad in 2017-2019. The highest response time was observed in the middle of summer and autumn. The figure reveals that the average response time and average scene interval time decreased, while the average time from leaving the patient's location to arriving at hospital increased.

Figure 4 shows the distribution of CVD-related emergency calls according to daily time periods. The highest number of calls occurred between 9 p.m. and 1 a.m., and the lowest number of calls occurred between 3 a.m. and 9 a.m. This pattern was maintained throughout the entire period of study (2017-2019). Figure 5 shows the distribution of CVD-related emergency calls according to week days. Saturdays had the highest call volume across all 3 years. It is the first working day of the week in Iran.

Figure 6 shows the geographical distribution of CVDrelated emergency calls at the neighborhood level in the

Table 2 Characteristics of CVD-related emergency calls in the city of Mashhad from August 2017 until the end of 2019

\begin{tabular}{|c|c|c|c|c|c|}
\hline Characteristics & & $\begin{array}{l}\text { All patients } \\
(n=84,559)\end{array}$ & $\begin{array}{l}2017 \\
\text { (23 Aug-30 Dec) }\end{array}$ & $\begin{array}{l}2018 \\
\text { (1 Jan- } 30 \text { Dec) }\end{array}$ & $\begin{array}{l}2019 \\
\text { (1 Jan- } 30 \mathrm{Dec})\end{array}$ \\
\hline Mean age $\pm \operatorname{SD}(n=84,559)$ & & $52.83 \pm 30.44$ & $53.58 \pm 21.52$ & $52.63 \pm 23.04$ & $52.78 \pm 37.64$ \\
\hline Men mean age \pm SD & & $51.95 \pm 39.04$ & $52.49 \pm 20.81$ & $51.72 \pm 26.08$ & $51.98 \pm 50.72$ \\
\hline Women mean age \pm SD & & $53.60 \pm 20.33$ & $54.58 \pm 22.00$ & $53.40 \pm 20.12$ & $53.48 \pm 19.99$ \\
\hline Male $(n ; \%)$ & & $38,998(46.13 \%)$ & $5334(46.28 \%)$ & $15,570(45.32 \%)$ & $18,094(46.80 \%)$ \\
\hline Response time & $\begin{array}{l}\text { mean } \pm S D \\
(n=80,747)\end{array}$ & $11.35 \pm 6.5$ & $12.33 \pm 5.48$ & $11.36 \pm 6.46$ & $11.07 \pm 6.77$ \\
\hline Scene interval time & $\begin{array}{l}\text { mean } \pm \text { SD } \\
(n=51,978)\end{array}$ & $13.02 \pm 7.77$ & $14.83 \pm 11.21$ & $12.71 \pm 6.56$ & $12.81 \pm 7.53$ \\
\hline Leave location time - hospital arrival time & $\begin{array}{l}\text { mean } \pm \text { SD } \\
(n=42,649)\end{array}$ & $11.69 \pm 8.63$ & $10.21 \pm 11.47$ & $11.54 \pm 8.19$ & $12.13 \pm 8.17$ \\
\hline Number of call (monthly Average) & & $84,239(2977)$ & $11,533(2685)$ & $34,361(2863)$ & $38,328(3194)$ \\
\hline \multicolumn{6}{|l|}{ Action Result ( $n=84,239 ; \%)$} \\
\hline Transport to medical center & & $52,124(61.64 \%)$ & $6883(59.68 \%)$ & $21,626(62.94 \%)$ & $23,615(61.08 \%)$ \\
\hline $\begin{array}{l}\text { Lack of patient cooperation and refused } \\
\text { transfer to hospital }\end{array}$ & & $29,339(34.70 \%)$ & $4171(36.17 \%)$ & $11,719(34.11 \%)$ & $13,449(34.78 \%)$ \\
\hline $\begin{array}{l}\text { The patient died before the ambulance } \\
\text { arrived }\end{array}$ & & $2218(2.62 \%)$ & $320(2.77 \%)$ & $797(2.32 \%)$ & 1101 (2.85\%) \\
\hline $\begin{array}{l}\text { Basic services provided by emergency } \\
\text { technicians with patients recommended to } \\
\text { attend a medical center }\end{array}$ & & 878 (1.04\%) & 159 (1.38\%) & 219 (0.64\%) & $500(1.29 \%)$ \\
\hline
\end{tabular}

Response time or "Call receipt time - arrival time": time interval between the time when the call is made and the time when the emergency ambulance reaches the patient [23]; Scene interval time: the time duration of the presence of emergency technician at the scene [23]; (Leave location time - hospital arrival time): The time period between ambulances leaves patient location to the hospital [23] 


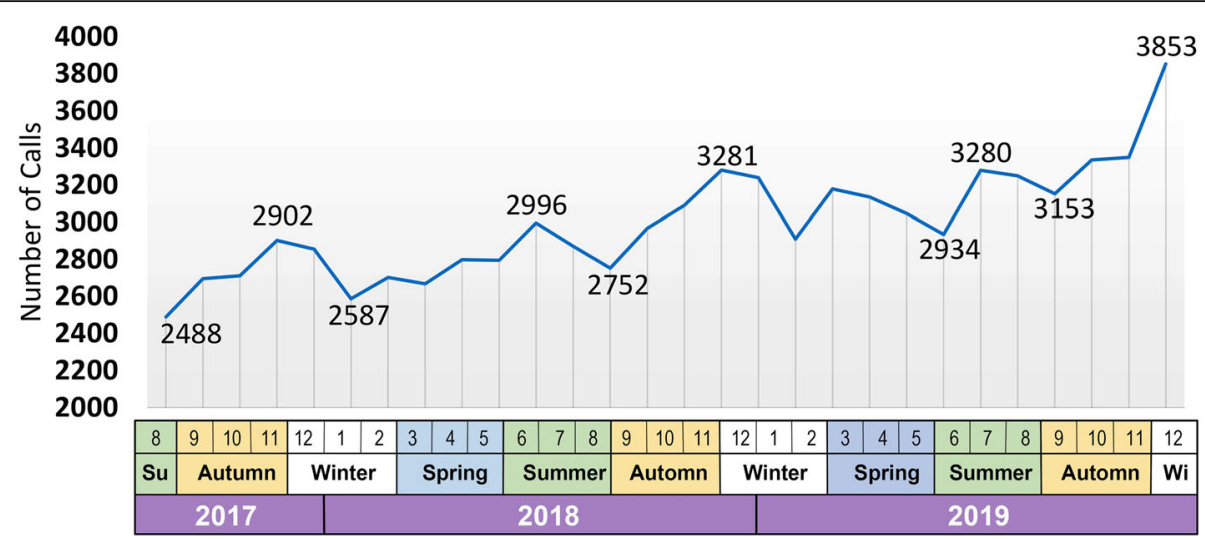

Fig. 2 Monthly frequency of CVD-related emergency calls in the city of Mashhad, Iran during 2017-2019

city of Mashhad, Iran. This graph highlights that there was a high-high cluster of the incidence of the CVDrelated calls in the south-eastern area of Mashhad.

Figure 7 shows the geographical distribution of call-tohospital time, response time, and scene-to-hospital time of emergency CVD-related medical calls in Mashhad from August 2017 until the end of 2019.

Figure 8 shows that call-to-hospital-arrival time and scene-to-hospital-arrival time are the same in terms of geographical distribution at neighborhood level. However, spatial distribution of response time is different from both call-to-hospital-arrival-time and scene-tohospital-arrival time.

Figure 9 shows the areas where CVD-related mortality is significantly higher and high-high clusters of mortality were observed in center-south part of the study area.

\section{Discussion}

The main aim of the present study was to estimate and visualize EMS response time for CVD-related calls between 2017 and 2019. Our main findings suggest that there is a significant variation in EMS response time over space and time, with significant clusters of low/or high response time and CVD-related mortality in Mashhad.

Previous studies highlight that clinical events and calls to clinical emergency services are not random, and follow a regular pattern. This pattern depends on the specific daily time period, levels of car traffic, places of residence and commuting throughout the city, and other epidemiologic and demographic factors [19]. Sudden myocardial infarctions, for example, follow a regular pattern of occurrence [24-27], with most events occurring between morning and noon [28, 29]. Moreover, some studies report seasonal or weekly patterns of occurrence of myocardial events, with a reported increase on Mondays [30-33]. Our study findings highlighted that the number of emergency requests follows a pattern of increased incidence between morning and noon, in line with the findings of previous studies. Moreover, we also

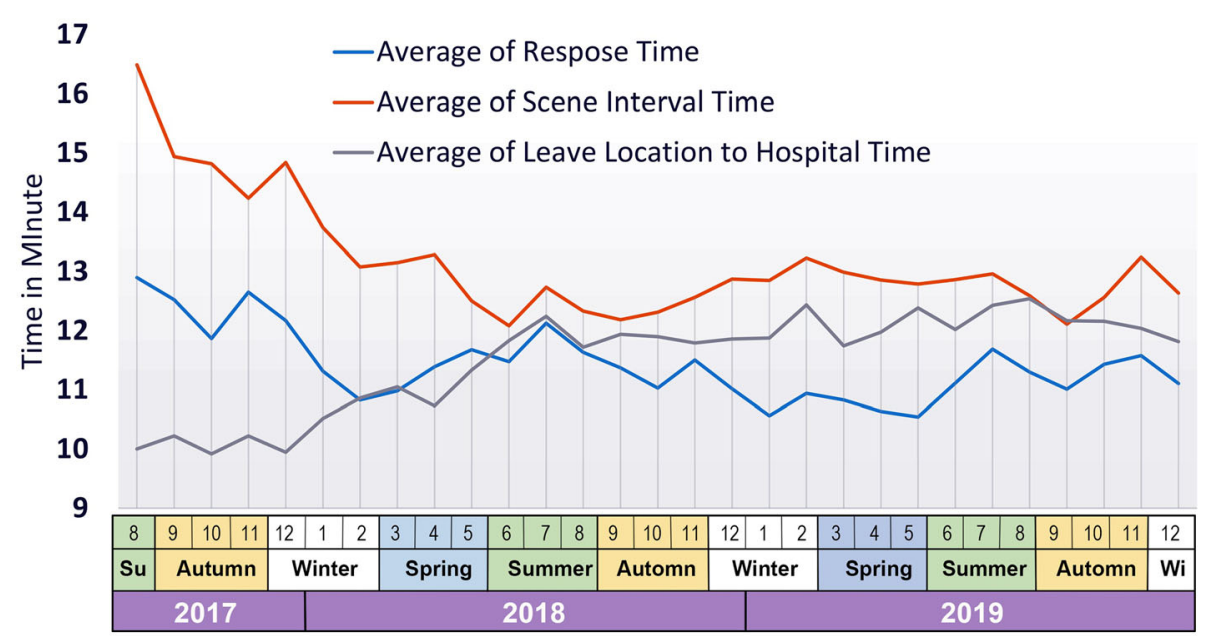

Fig. 3 Seasonal distribution of cardiovascular-related calls in the city of Mashhad, Iran in 2017-2019 


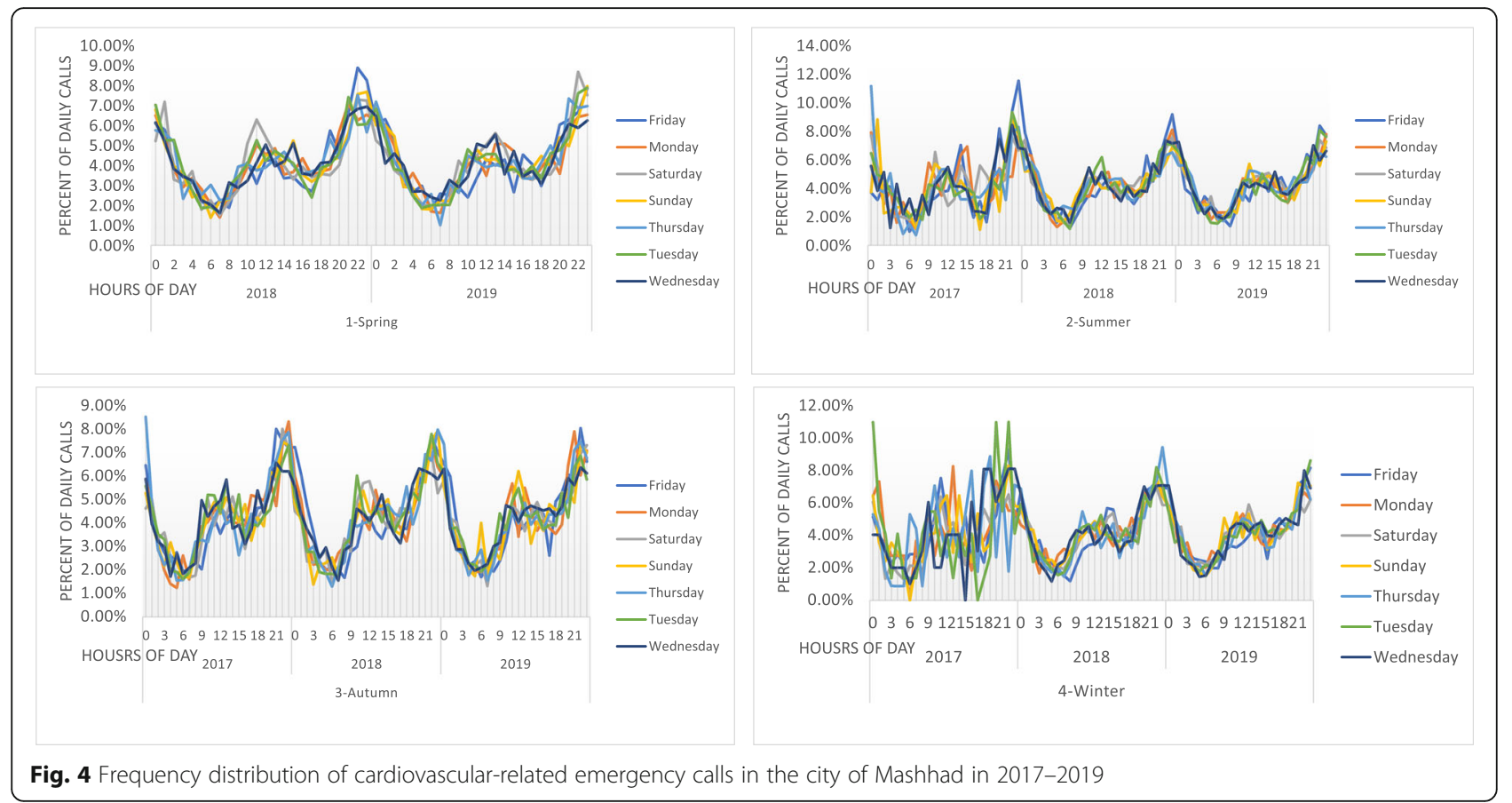

observed an increasing pattern of emergency calls between $6 \mathrm{pm}$ and midnight. This pattern was observed consistently across all days of the week from 2017 to 2019 (Fig. 4). Given the fact that a previous study [34] identified sudden wake-up and heavy workload as the main risk factors for myocardial infarction, these two factors could explain the higher rate of incidence in the morning (sudden wake-up) and evening (heavy workload). Moreover, while in some studies the weekly pattern of peak incidence rate was identified as occurring on Mondays, in our study this was found to be Saturdays
(Fig. 5). This is likely to be due to the difference between the working week in Iran and that of the rest of the world. In Iran, Saturday is the first day of the week, and Friday is considered to be the weekend. The lowest rate of calls was recorded on Thursdays in the first year of study, and on Fridays in the second and third year of the study. Although Fig. 2 shows that the volume of emergency services delivered increased between 2017 and 2018 by 7\%, and between 2017 and 2019 by 19\%, the overall ratio of cardiovascular-related emergency services to total number of emergency services delivered was 17.4, 17.5, and 17.3 for

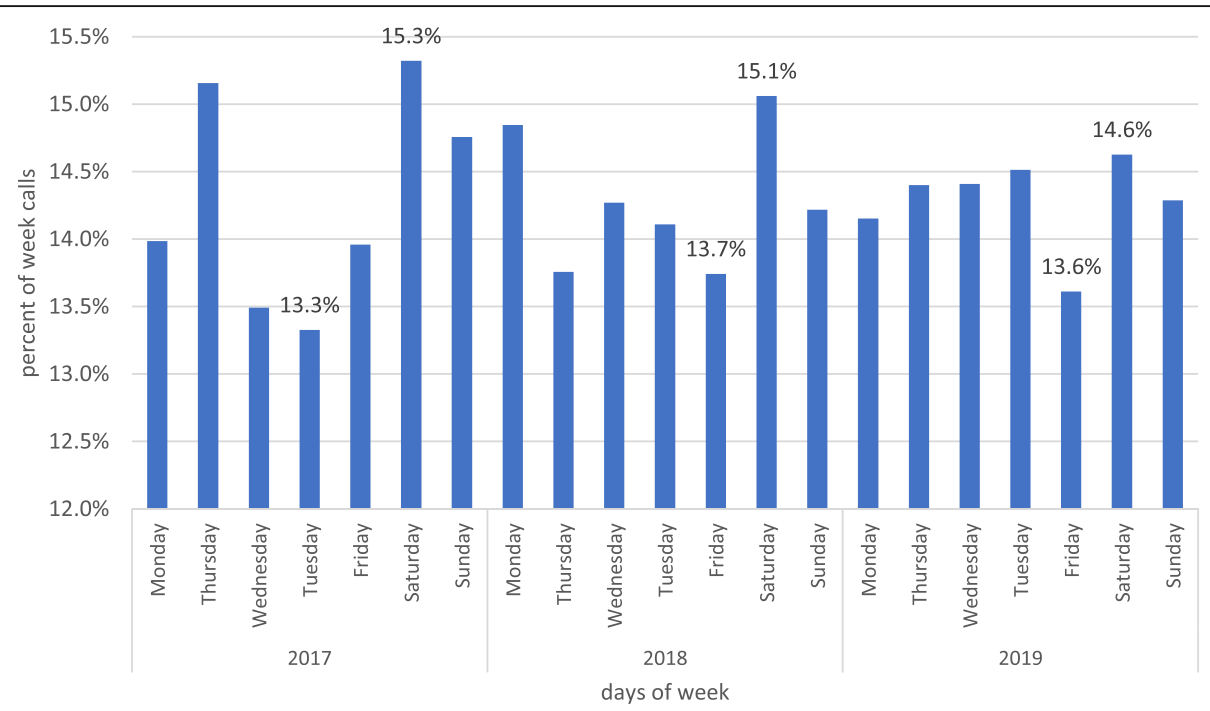

Fig. 5 Frequency distribution of cardiovascular-related emergency calls in the days of the week in the city of Mashhad in 2017-2019 

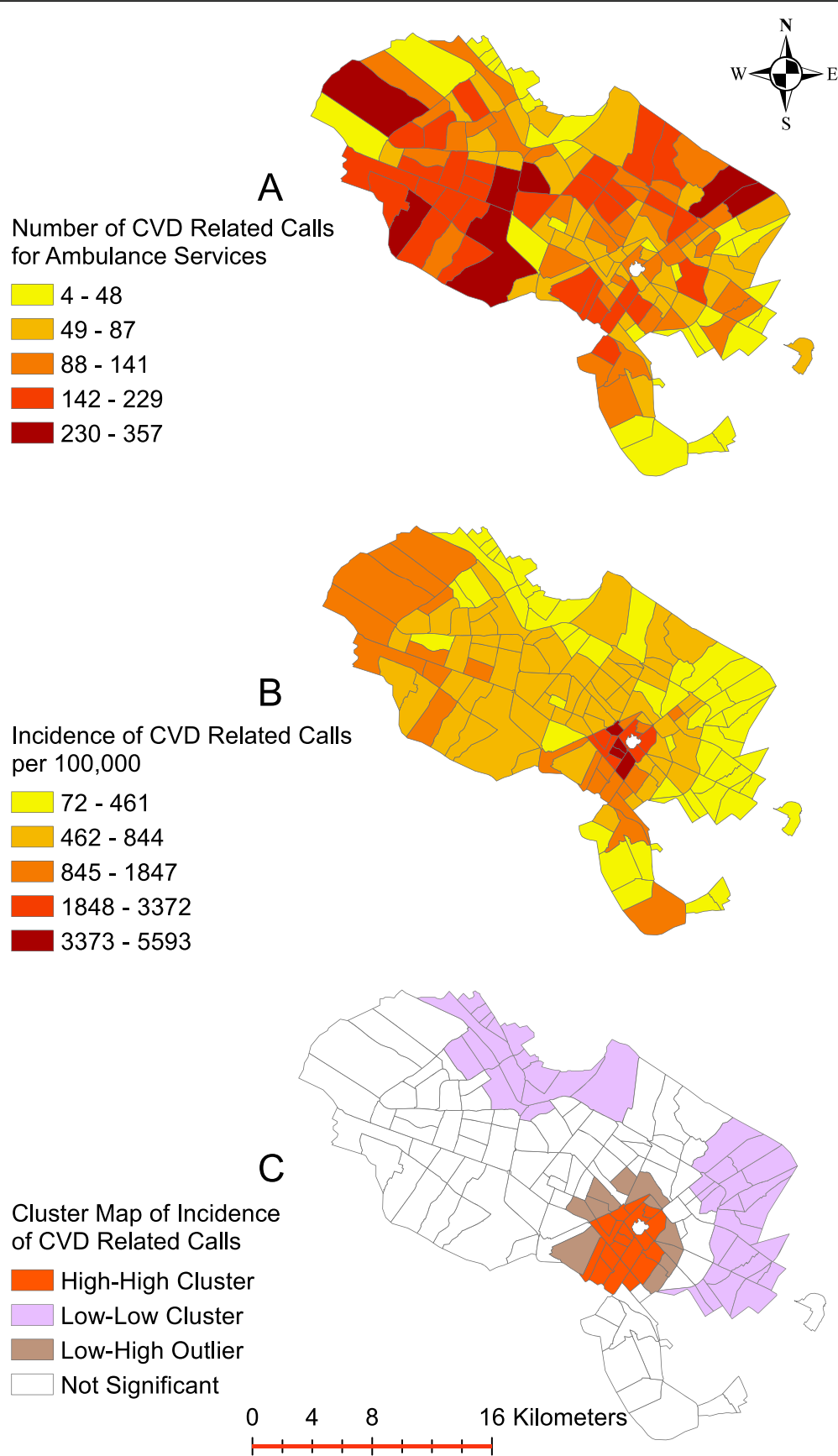

Fig. 6 Frequency, incidence per 100,000 and incidence cluster map of cardiovascular-related emergency medical calls related to cardiovascular problems in city of Mashhad between 2017 and 2019

the past three calendar years, respectively. We could therefore interpret this to mean that not only CVD call requests, but all emergency calls, have increased. Furthermore, it is important to note that while these 84,329 CVD-related emergency request calls were based on symptoms interpreted by the caller as CVD related, such as chest pain, ultimately some of these calls were found not to be associated with CVD, and were instead indicators of other types of disease or disorders.
Figure 6 shows the spatial distribution of EMS calls, demonstrating that the south-eastern areas of Mashhad have the highest number of emergency service requests. This is an area in proximity to the Holy Shrine, which is a central tourist destination and a pilgrimage location. It is an area with a high concentration of hotels, residential complexes and shopping malls. As such, there is a high population density and heavy traffic congestion in this area compared to the rest of Mashhad. 


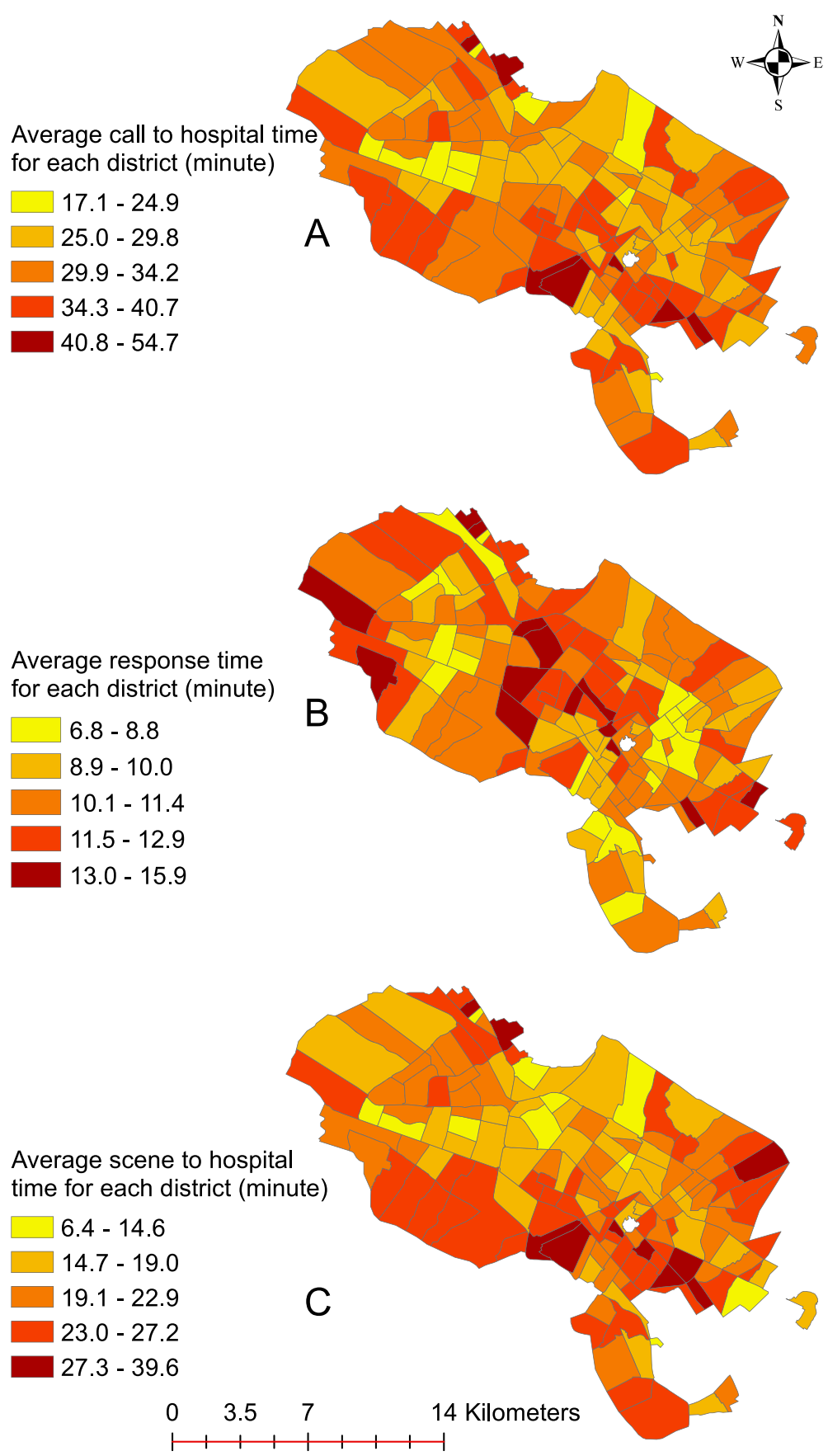

Fig. 7 Call to hospital time, response time, and scene to hospital time map of emergency medical calls related to cardiovascular problems in city of Mashhad between 2017 and 2019

The most important temporal criterion in assessing the performance of pre-hospital emergency services is response time. The standard response time is $8 \mathrm{~min}$, which is directly related to higher survival rate and reduced mortality. The average response time for the three consecutive years was calculated as $11.35 \pm 6.5 \mathrm{~min}$, showing a pattern of decreasing response times: $12.33 \pm$ 5.48 in $2017,11.36 \pm 6.46$ in 2018 and $11.07 \pm 6.77$ in
2019. Another important criterion in assessing the performance of pre-hospital emergency services is scene interval, which represents the duration of time when emergency technicians are present at the scene. Patients should be managed in such a way so as to minimize delays in their transfer to clinical centers. The global gold standard for this criterion is $10 \mathrm{~min}$ [35]. In Iran, scene interval is typically less than $20 \mathrm{~min}$ [23]. The average 
Cluster map of call to hospital time

Not Significant

High-High Cluster

High-Low Outlier

Low-High Outlier

Low-Low Cluster

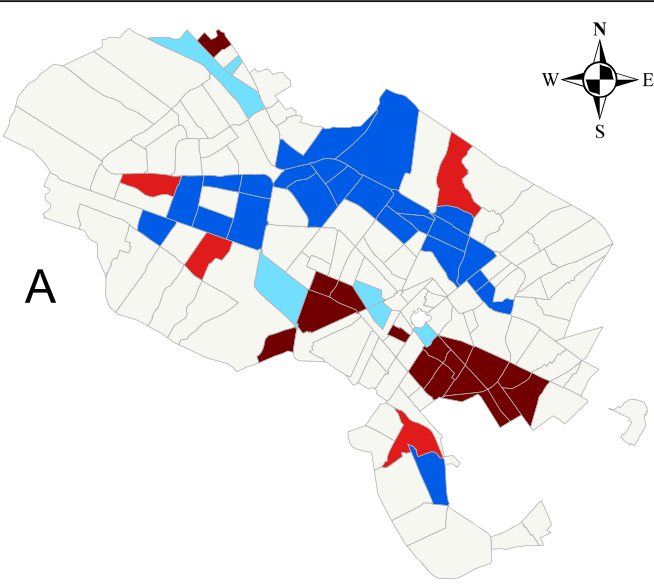

Cluster map
of response time

of response time
Not Significant

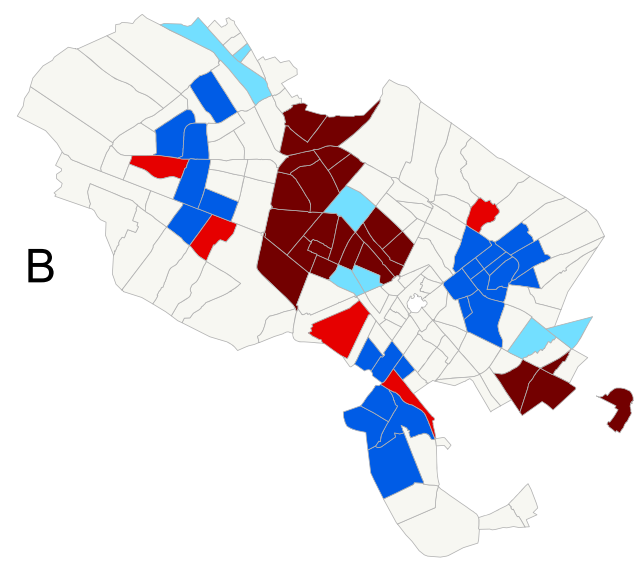

High-High Cluster

High-Low Outlier

Low-High Outlier

Low-Low Cluster

Cluster map

of scene to hospital time

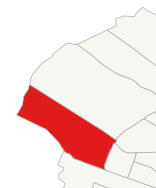

Not Significant

High-High Cluster

High-Low Outlier

Low-High Outlier

Low-Low Cluster

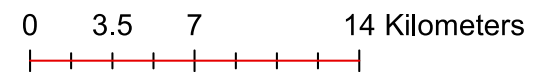

Fig. 8 Call to hospital time, response time, and scene to hospital time cluster map of emergency medical calls related to cardiovascular problems in city of Mashhad between 2017 and 2019

scene interval was calculated as $13.02 \pm 7.77 \mathrm{~min}$ for the past consecutive 3 years, showing a decreasing pattern. Although both these criteria lag far behind global standards, this difference is not uniformly distributed across different areas of the city (Figs. 7).

Cluster maps in Fig. 8 show significant differences in the performance of emergency departments across different areas of the city in relation to temporal criteria.
A thorough analysis reveals that in the central areas of the city, where response time is high, there is no problem in terms of call to hospital time and scene to hospital time. The high response time may relate to a high volume of calls in this area due to its population density, leading to an increased response time in the central area of Mashhad. On the contrary, in the southern and rural areas of the city, which have a good 


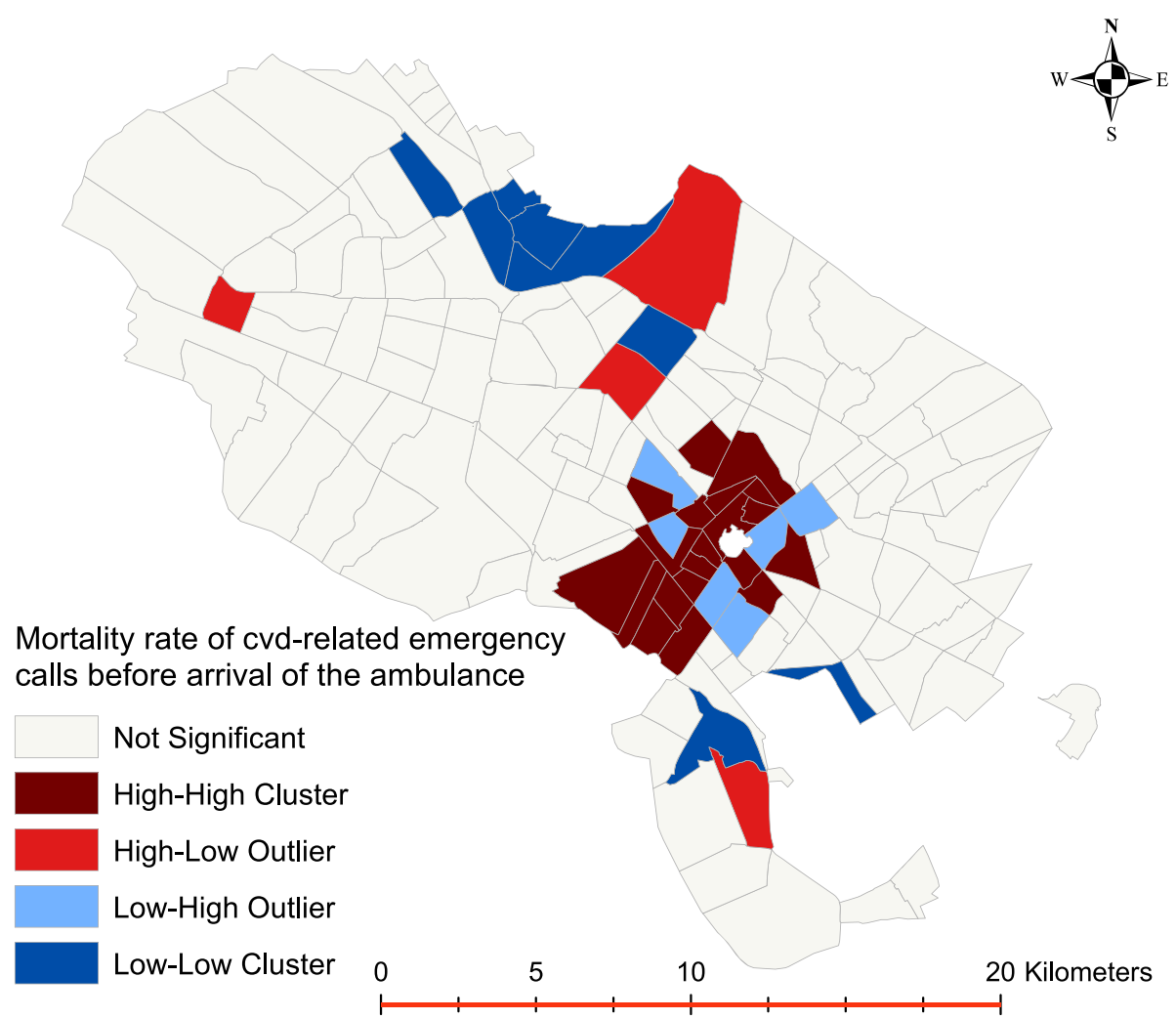

Fig. 9 Mortality cluster map of CVD-related emergency calls before arrival of the ambulance to the patient location

response time, a weak call to hospital time and scene to hospital time is observed. This problem is likely due to the fact that the location of emergency dispatch centers is not properly linked with their respective hospitals. This should be taken into account to improve healthcare standards and survival rate of patients.

The cluster map of Fig. 9 shows the mortality rate of patients with myocardial infarction who died before ambulance arrival. As can be observed, the south eastern area is associated with a significantly higher risk of mortality when compared to other areas. An analysis of the mean age for these subjects indicates that they have a higher mean age $(71.91 \pm 20.07)$. This is observed across all 3 years.

Previous studies report that a higher response time is directly associated with a higher rate of mortality [36]. Although the response time is shorter in this group of patients (9.62-min vs 11.35 for the entire population), the mortality rate is higher as compared to that of the total population. This needs to be investigated further to identify other drivers (risk factors) of CVD-related mortality besides response time. Some of these risk factors have been identified in previous studies and include patients' age, delays in requesting emergency services, previous history of disease, lack of knowledge about heart disease, and loneliness and life style [37, 38]. Given that the mean age of this group of patients is significantly higher than the rest of the population, it could be speculated that because of the higher age, other factors such as loneliness, low health literacy, previous disease history (more advanced disease, more comorbidities as a result of older age) could be the most significant driver of increased mortality despite quick response time in older individuals.

\section{Limitations}

No data was available on the time interval between the onset of chest cardiac symptoms and the decision by the patient to request emergency services, which is an important determining factor for patient survival. Furthermore, we did not use age-standardized rates for comparison. Also, the issue of Modified Unit Area Problem remains inherent to the studies that focus on aggregated spatial datasets.

\section{Conclusion}

The use of geographical information systems and spatial analyses in modelling and quantifying EMS response time provides a new vein of knowledge for decision makers in emergency services management. Spatial as well as temporal clustering of EMS calls were present in the study area. The reasons for clustering of unfavorable 
time indices for EMS response requires further exploration. This approach enables policymakers to design tailored interventions to improve response time and reduce CVDrelated mortality.

\section{Abbreviations}

CVD: Cardiovascular disease; CAD: Coronary artery disease; MI): Myocardial infarction; EMS: Emergency medical services; GIS: Geographical information systems

\section{Acknowledgements}

We thank the Mashhad EMS center for obtaining the data presented in this study.

\section{Authors' contributions}

B.K, A. A and M. M and N. B drafted the manuscript. N. B and M. F critically reviewed and edited the first draft. S. H contributed to spatial analyses. F.HA geocoded the data. S. E reviewed the manuscript and contributed to study design. B. K designed the study, interpret the results and supervised the research. R. V, F. K, A. G and T. A contributed to data cleaning and preparing the data for analyses. All authors read and approved the final manuscript for submission.

\section{Funding}

This study was financially sponsored by Mashhad University of Medical Sciences (Project grant: 980861)

\section{Availability of data and materials}

The datasets used and/or analyzed during the current study are available to the public from the corresponding author (B.K) on reasonable request.

\section{Ethics approval and consent to participate}

The study was approved by the ethics committee of the Research Department of Mashhad University of Medical Sciences protocol number: IR.MUMS.MEDICAL.REC.1399.146. Inform consent was not obtained due to the nature of the study and the ethical committee approved that.

\section{Consent for publication}

Not applicable because we used the data of EMS center which did not include any identification items.

\section{Competing interests}

The authors declare that they have no competing interests.

\section{Author details}

${ }^{1}$ Department of Medical Informatics, School of Medicine, Mashhad University of Medical Sciences, Mashhad, Iran. ${ }^{2}$ Center for Mental Health Research College of Health and Medicine, Australian National University, Canberra, Australian Capital Territory, Australia. ${ }^{3}$ Center for Accident and Emergency Medicine Management, Mashhad University of Medical Sciences, Mashhad, Iran. ${ }^{4}$ Student Research Committee, School of Health, Mashhad University of Medical Sciences, Mashhad, Iran. ${ }^{5}$ Department of Health Information Technology, Shahroud University of Medical Sciences, Shahroud, Iran.

Received: 23 September 2020 Accepted: 14 December 2020 Published online: 04 January 2021

\section{References}

1. Fullman N, Yearwood J, Abay SM, Abbafati C, Abd-Allah F, Abdela J, Abdelalim A, Abebe Z, Abebo TA, Aboyans V, Abraha HN. Measuring performance on the Healthcare Access and Quality Index for 195 countries and territories and selected subnational locations: a systematic analysis from the Global Burden of Disease Study 2016. The Lancet. 2018;391(10136):223671. https://doi.org/10.1016/S0140-6736(18)30994-2.

2. Collaborators GBDCoD. Global, regional, and national age-sex specific mortality for 264 causes of death, 1980-2016: a systematic analysis for the Global Burden of Disease Study 2016. Lancet (London, England). 2017; 390(10100):1151-210.

3. Naghavi M, Marczak LB, Kutz M, Shackelford KA, Arora M, Miller-Petrie M, et al. Global mortality from firearms, 1990-2016. Jama. 2018;320(8):792-814.
4. Mendissh PP, Norrving B, Alwan A, Armstrong T, Bettcher D, Boerma T, Branca F, Ho JCY, Mathers C, VP RM, Roglic G, Riley L, d'Espaignet E, Stevens $G$, Taubert K, Xuereb G. Others who, provided assistance in various ways in the compilation of this document include A. In: Ayinla XB, Besson F, AE LB, Christenson N, Lubega F, Nordet P, Osekre-Amey M, Tarel J, editors. Global atlas on cardiovascular disease prevention and control; 2011.

5. Thygesen K, Alpert JS, White HD, TASK FORCE MEMBERS: Chairpersons: Kristian Thygesen JSA, Harvey D. White *, Biomarker Group: Allan S. Jaffe C, Fred S. Apple, Marcello Galvani , Hugo A. Katus, L. Kristin Newby, Jan Ravkilde, ECG Group: Bernard Chaitman C-o, Peter M. Clemmensen, Mikael Dellborg, Hanoch Hod, Pekka Porela, et al. Universal definition of myocardial infarction. Circulation. 2007;116(22):2634-53.

6. O'Gara PT, Kushner FG, Ascheim DD, Casey DE Jr, Chung MK, de Lemos JA, et al. 2013 ACCF/AHA guideline for the management of ST-elevation myocardial infarction: executive summary: a report of the American College of Cardiology Foundation/American Heart Association Task Force on practice guidelines. J Am Coll Cardiol. 2013;61(4):485-510.

7. Rollando D, Puggioni E, Robotti S, De Lisi A, Ferrari Bravo M, Vardanega A, et al. Symptom onset-to-balloon time and mortality in the first seven years after STEMI treated with primary percutaneous coronary intervention. Heart. 2012;98(23):1738-42.

8. Saberian P, Tavakoli N, Ramim T, Hasani-Sharamin P, Shams E, Baratloo A. The role of pre-hospital Telecardiology in reducing the coronary reperfusion time; a brief report. Arch Acad Emerg Med. 2019;7(1):e15.

9. Goshayeshi L, Pourahmadi A, Ghayour-Mobarhan M, Hashtarkhani S, Karimian S, Shahhosein Dastjerdi R, Eghbali B, Seyfi E, Kiani B. Colorectal cancer risk factors in north-eastern Iran: A retrospective cross-sectional study based on geographical information systems, spatial autocorrelation and regression analysis. Geospatial Health. 2019;14(2). https://doi.org/10.4081/gh. 2019.793.

10. Halimi L, Bagheri N, Hoseini B, Hashtarkhani S, Goshayeshi L, Kiani B. Spatial analysis of colorectal cancer incidence in Hamadan Province, Iran: a retrospective cross-sectional study. Appl Spatial Anal Pol. 2020;13(2):293-303. https://doi.org/10.1007/s12061-019-09303-9.

11. Hashtarkhani S, Kiani B, Bergquist R, Bagheri N, VafaeiNejad R, Tara M. An age-integrated approach to improve measurement of potential spatial accessibility to emergency medical services for urban areas. Int J Health Planning Manag. 2020;35(3):788-98. https://doi.org/10.1002/hpm.2960.

12. Hoseini B, Bagheri N, Kiani B, Azizi A, Tabesh H, Tara M. Access to dialysis services: a systematic mapping review based on geographical information systems. Geospat Health. 2018;13(1):3-10.

13. Kiani B, Bagheri N, Tara A, Hoseini B, Tabesh H, Tara M. Revealed access to haemodialysis facilities in northeastern Iran: factors that matter in rural and urban areas. Geospat Health. 2017;12:584.

14. Shabanikiya H, Hashtarkhani S, Bergquist R, Bagheri N, VafaeiNejad R, AmiriGholanlou M, et al. Multiple-scale spatial analysis of paediatric, pedestrian road traffic injuries in a major city in north-eastern Iran 2015-2019. BMC Public Health. 2020;20:1-11.

15. Burrough PA, McDonnell R, McDonnell RA, Lloyd CD. Principles of geographical information systems: Oxford university press; 2015.

16. Xia T, Song X, Zhang H, Song X, Kanasugi H, Shibasaki R. Measuring spatiotemporal accessibility to emergency medical services through big GPS data. Health Place. 2019;56:53-62.

17. Chen CC, Chen CW, Ho CK, Liu IC, Lin BC, Chan TC. Spatial variation and resuscitation process affecting survival after out-of-hospital cardiac arrests (OHCA). PLoS One. 2015;10(12):e0144882.

18. Earnest A, Hock Ong ME, Shahidah N, Min Ng W, Foo C, Nott DJ. Spatial analysis of ambulance response times related to prehospital cardiac arrests in the city-state of Singapore. Prehospital Emerg Care. 2012;16(2):256-65.

19. Ong ME, Ng FS, Overton J, Yap S, Andresen D, Yong DK, et al. Geographictime distribution of ambulance calls in Singapore: utility of geographic information system in ambulance deployment (CARE 3). Ann Acad Med Singap. 2009;38(3):184-91.

20. Ong ME, Earnest A, Shahidah N, Ng WM, Foo C, Nott DJ. Spatial variation and geographic-demographic determinants of out-of-hospital cardiac arrests in the city-state of Singapore. Ann Emerg Med. 2011;58(4):343-51.

21. Kafashpor A, Ghasempour Ganji SF, Sadeghian S, Johnson LW. Perception of tourism development and subjective happiness of residents in Mashhad, Iran. Asia Pacific J Tourism Res. 2018:23(6):521-31. 
22. Chen J, Yang S, Li H, Zhang B, LV J. Research on geographical environment unit division based on the method of natural breaks (Jenks). Int Arch Photogramm Remote Sens Spat Inf Sci. 2013;3:47-50. https://doi.org/10. 5194/isprsarchives-XL-4-W3-47-2013.

23. Deputy of the Ministry of Health MEaDC e. Operational processes of prehospital emergency instructions; 2016. p. 1-75.

24. Willich SN, Levy D, Rocco MB, Tofler GH, Stone PH, Muller JE. Circadian variation in the incidence of sudden cardiac death in the Framingham heart study population. Am J Cardiol. 1987;60(10):801-6.

25. Savopoulos C, Ziakas A, Hatzitolios A, Delivoria C, Kounanis A, Mylonas S, et al. Circadian rhythm in sudden cardiac death: a retrospective study of 2,665 cases. Angiology. 2006;57(2):197-204.

26. Jones-Crawford JL, Parish DC, Smith BE, Dane FC. Resuscitation in the hospital: circadian variation of cardiopulmonary arrest. Am J Med. 2007; 120(2):158-64

27. Vallabhajosyula S, Patlolla SH, Cheungpasitporn W, Holmes DR Jr, Gersh BJ. Influence of seasons on the management and outcomes acute myocardial infarction: an 18-year US study. Clin Cardiol. 2020;43(10):1175-85.

28. Ong ME, Ng FS, Yap S, Yong KL, Peberdy MA, Ornato JP. Temporal variation of out-of-hospital cardiac arrests in an equatorial climate. Open Access Emerg Med. 2010;2:37.

29. Szczerbiński S. Observational, retrospective analysis of the circadian variability of out-of-hospital cardiac arrest within days of the week. Med Res J. 2020;5(2):68-71.

30. Arntz HR, Willich SN, Schreiber C, Brüggemann T, Stern R, Schultheiss HP. Diurnal, weekly and seasonal variation of sudden death. Population-based analysis of 24,061 consecutive cases. Eur Heart J. 2000;21(4):315-20.

31. Arntz HR, Müller-Nordhorn J, Willich SN. Cold Monday mornings prove dangerous: epidemiology of sudden cardiac death. Curr Opin Crit Care. 2001;7(3):139-44

32. Gruska M, Gaul GB, Winkler M, Levnaic S, Reiter C, Voracek M, et al. Increased occurrence of out-of-hospital cardiac arrest on Mondays in a community-based study. Chronobiol Int. 2005;22(1):107-20.

33. Willich SN, Löwel H, Lewis M, Hörmann A, Arntz HR, Keil U. Weekly variation of acute myocardial infarction. Increased Monday risk in the working population. Circulation. 1994;90(1):87-93.

34. Jafari H, Shafipour V, Mokhtarpour R, Rahnama N, Esmaeili R, Nasiri E. Study of some risk factors and accelerating factors of heart attack and the delay reasons in referring to the Mazandaran cardiac center in 2009. Mazandaran Univ Med Sci. 2010;19(73):68.

35. Raeissi P, Nasiripour A, Lotf S, Abrisham A, Akbarzde M. An investigation of the relationship between job characteristics of emergency medical technicians and scene time in traumatic injuries of Mashhad. J Pol Med. 2013;2(1):47-54.

36. Moradian MJ, Peyravi MR, Ettehadi R, Pourmohammadi K. Studying the Time of Response and Results of Delay in Emergency Medical System. Quarterly Sci J Rescue Relief. 2013;5(2):39.

37. Rahmani R, Hamidi Z, Karimi Zarchi A, Salari MM. Evaluation of trigger factors incidence of time and delaying factors in patients with acute myocardial infarction. Kowsar Med J. 2006;11(3):273-8.

38. Taghadosi M, Seyedi SM, Moosavi GA. Assesment of delayed treatment in patients with acute myocardial infarction at Kashan Shaheed Beheshtee Hospital during 2003-2005. J Kashan Univ Med Sci. 2007;11(3):45-51.

\section{Publisher's Note}

Springer Nature remains neutral with regard to jurisdictional claims in published maps and institutional affiliations.

Ready to submit your research? Choose BMC and benefit from:
- fast, convenient online submission
- thorough peer review by experienced researchers in your field
- rapid publication on acceptance
- support for research data, including large and complex data types
- gold Open Access which fosters wider collaboration and increased citations
- maximum visibility for your research: over 100M website views per year
At BMC, research is always in progress.
Learn more biomedcentral.com/submissions

